Sheehy A, Smith R, Gray JE, Homer CSE. Midwifery pre-registration education and mid-career workforce participation and experiences. Midwifery pre-registration education and mid-career workforce participation and experiences, Women and Birth, 2019, 32 (2), pp. e182 e188, http://hdl.handle.net/10453/135583

\title{
MIDWIFERY PRE-REGISTRATION EDUCATION AND MID-CAREER WORKFORCE PARTICIPATION AND EXPERIENCES
}

\begin{abstract}
Background

Midwives in Australia are educated through a range of routes providing flexible ways to become a midwife. Little is known about whether the route to registration impacts on mid-career experiences, in particular, whether the pathway (post-nursing pathway compared with 'direct-entry') makes any difference.
\end{abstract}

\section{Aim}

The aim of this study was to explore the midwifery workforce experiences and participation in graduates six to seven years after completing either a post-nursing Graduate Diploma in Midwifery (GradDip) or an undergraduate degree, the Bachelor of Midwifery (BMid), from one university in New South Wales, Australia.

\section{Methods}

Data were collected from mid-career midwives having graduated from one NSW university from 2007-2008 using a survey. The survey included validated workforce participation instruments - the Maslach Burnout Inventory (MBI), the Practice Environment Scale-Nursing Work Index (PES-NWI) and the Perceptions of Empowerment in Midwifery Scale (PEMS).

\section{Results}

There were 75 respondents: 40\% (n=30) BMid and 60\% (n=45) GradDip graduates. The age range was 27 to 56 years old (mean age $=36$ years) BMid graduates being on average 7.6 years older than GradDip graduates (40 vs 33 yrs; $p<0.01$ ). Almost $80 \%$ (59), were currently working in midwifery. Nine of the 12 not working in midwifery (75\%) planned to return. There were no differences in 
workforce participation measures between the two educational pathways. Working in a continuity of care model was protective in regards to remaining in the profession.

\section{Conclusion}

Most mid-career graduates were still working in midwifery. There were no differences between graduates from the two pathways in relation to burnout, practice experiences or perceptions of empowerment.

\section{Statement of Significance}

Issue

There is limited midwifery-specific workforce data available in Australia. It is not clear whether the experiences of early to mid-career midwives (6-7 years post registration) differ by educational preparation, in particular, whether a post-nursing pathway (GradDip) differs from the 'direct-entry' (BMid) pathway.

\section{What is known?}

New graduate midwives require support both professionally and emotionally in the initial career years. As careers continue, several aspects make it more likely for midwives to remain in the profession and to flourish and these are occupational autonomy, social support and the ability to develop meaningful relationships.

\section{What this paper adds?}

This paper provides midwifery specific career trajectory information particularly in relation to understanding if workforce participation trends differ between graduates prepared through the Bachelor of Midwifery and those through the post-nursing Graduate Diploma in Midwifery. Results indicate, no differences in workforce participation and retention measures are evident. Sub analysis supports the provision of continuity of midwifery care and reduced burnout measures. 


\section{INTRODUCTION}

The provision of quality maternal and newborn health care is reliant upon having a professional, competent and effective midwifery workforce. ${ }^{1}$ Supporting the smooth entry of new midwives into the profession is important as they are a valuable resource. The period of transition from a midwifery student into midwife can be confronting, overwhelming and often involves a period of acculturation whereby individuals are required to align personal and professional expectations with the reality of encountered workforce experiences. ${ }^{2,3}$ This early career period and the next five to 10 years are critical to build capacity and reduce unnecessary attrition.

Currently in Australia, there are a number of pathways for entry to practice as a midwife. These include a post-nursing (Bachelor, Post-Graduate Diploma or Masters level) route, an undergraduate midwifery degree (Bachelor of Midwifery) and an undergraduate double degree (Bachelor of Nursing/Bachelor of Midwifery). ${ }^{4}$ Undergraduate midwifery education is a relative newcomer to Australian tertiary education with the first graduates entering the workforce in $2005 . .^{4,5}$ Despite different pathways for entry to practice, all pre-registration midwifery programs are accredited using the same standards and all produce graduates who meet national midwifery competency standards. ${ }^{6}$ Regardless of program pathway, the majority of these new graduates commence their career in a new-graduate supported program through the public or private health system.

Detailed information about the midwifery workforce trends and projections is lacking in Australia with the last specific analysis conducted in $2012 .{ }^{7}$ Understanding the elements that constitute the work experiences of midwives in their first five to seven years is critical when considering that, like other countries across the globe, there exists current and predicted shortages of the health workforce and this includes midwifery. ${ }^{7,8}$ In addition, the rising average age of midwives, in line with the ageing population, is putting further pressure on the midwifery workforce. ${ }^{9}$ Understanding the elements that constitute both positive and negative work experiences of early to mid-career midwives may assist in informing or developing educational and workforce policies and practices that encourage workforce retention, reduced turnover and improved career satisfaction. 
Whilst some research has examined the initial year of practice in midwifery, often referred to as the new-graduate year, ${ }^{3,10-14}$ less is known about the mid-career years (for example, 6-7 years). Much of the midwifery workforce research has not separated early career respondents from those who are mid-career or those who are approaching the end of long midwifery careers. ${ }^{15-17}$ One Canadian study has examined attrition rates of midwives within the first six years of registration to better understand a workforce shortage ${ }^{18}$ Cameron ${ }^{18}$ theorised that entry into midwifery is often altruistic but the reality of work over time can be difficult to maintain due to high professional and personal demands. This high level of demand led to burnout and a reported 'loss of self' leading to decisions to leave the profession rather than losing the original sense of who they were as midwives. This finding is not dissimilar to Curtis et al in their 'Why Midwives Leave' study in the United Kingdom (UK) where midwives reported leaving because they were not able to be the kind of midwife they wanted to be ${ }^{19}$ Other reasons cited for leaving midwifery were dissatisfaction with the way some were required to practice; family commitments; planned career change; and, planned retirement or ill-health. ${ }^{19}$

Alternatively, the 'Why Midwives Stay' study, Kirkham et $\mathrm{al}^{20}$ identified that midwives stay as they enjoyed their job with a key source of satisfaction being able to build meaningful professional relationships with women and collegial relationships with colleagues. In addition to relationships, support in their private lives and job autonomy were also identified as key elements to staying in, and enjoying midwifery. Australian midwifery (and nursing) workforce retention studies found key aspects for staying in the profession(s) were being proud of the job, experiencing job satisfaction through relationships (with women) and experiencing a sense of autonomy. ${ }^{21,22}$ None of these studies however examined mid-career midwives specifically or looked at career experiences by education pathway.

Anecdotally, there have been concerns raised in the Australian health system that graduates from the different educational pathways may have different experiences and graduates from some 
cohorts may be more likely to leave. For example, some have been concerned that graduates also registered as nurses may return to nursing if midwifery does not meet their expectations.

Conversely, others raise concerns that Bachelor of Midwifery graduates may become burnt out and leave as they were not already socialised into hospital settings. Neither of these propositions have been examined. It is not clear whether the experiences of midwives in the mid-career period (post 67 years) differ by education pathway, in particular, whether a post-nursing pathway differs from the 'direct-entry' pathway. The aim of this study was to explore the midwifery workforce experiences and participation in graduates six to seven years after completing either a post-nursing Graduate Diploma in Midwifery (GradDip) or an undergraduate degree, the Bachelor of Midwifery (BMid), from one university in New South Wales, Australia. The study also examined rates of burnout, practice experiences and notions of empowerment in graduates who remained in the midwifery workforce.

\section{METHODS}

A survey design was used to collect mostly quantitative data (with some limited text-based opportunities to respond). Participants were identified through a longitudinal study which had recruited them when they were in their final semester of their pre-registration course in 2007 and $2008{ }^{14}$. At this time, all completing students eligible to register as midwives were invited to participate and 113 agreed, signed consent forms and provided contact details (99\% response rate). The research was approved by the University's Human Research Ethics Committee (HREC) (reference number 2007-219A).

The participants were contacted in 2013 and 2014 and invited to take part in this follow-up study. The six to seven year time interval was selected as it enabled examination of retention outside the initial early career period. Surveys were posted to all 113 potential participants and 75 participants responded (66\% response rate). 
Data were collected through a 79-question survey including three validated workforce related tools. Firstly, the Maslach Burnout Inventory (MBI), which consists of three sub-scales based on the framework developed in the original conceptualisation of burnout. ${ }^{23}$ These are emotional exhaustion, depersonalisation and reduced personal accomplishment. The MBI is regarded as the 'gold standard' burnout measurement tool and has been used in international midwifery and other health related professions research. ${ }^{24,25} \mathrm{MBI}$ validity and reliability has been substantiated in numerous studies, settings, occupations and cultures.

Secondly, the Practice Environment Scale-Nursing Work Index (PES-NWI) ${ }^{26}$ was used. The PES-NWI consists of five sub-scales based on participation in hospital affairs; presence of foundations of quality care (provision of preceptorship and continuous professional development programs); perceived leadership and support from managers and supervisory staff; staffing and resource adequacy; and, good working relationships between professions. This index is a reliable instrument for use in a range of clinical settings ${ }^{26}$ and has been adapted for use in midwifery. ${ }^{27}$

The third instrument was the Perceptions of Empowerment in Midwifery Scale (PEMS). ${ }^{28}$ This tool has three sub-scales, autonomous practice; effective management; and, perceptions of being 'woman-centred'. Although not as widely utilised as the MBI and PES-NWI, validity and reliability of the PEMS has been established. ${ }^{28}$

Written authority to use the PEMS and PES-NWI instruments was obtained from respective authors/developers and a license to use the MBI was purchased. Prior to distribution, the survey was piloted with 25 midwives in a variety of midwifery work settings. Minor adjustments to terminology occurred following the pilot results in order to aid clarity and midwifery context of practice.

The final paper-based survey was mailed to all recruited participants along with a text message to advise them the survey had been sent and a prepaid addressed reply envelope was included. Two further follow-up text messages were sent as completion reminders to those who had not returned surveys. 
The analysis was conducted using IBM SPSS Statistics 22 (SPSS). ${ }^{29}$ Simple descriptive statistics were calculated including frequency distributions and means of single variables within the sample and simple correlations descriptive analysis for measuring relationships between variables. Nonparametric analysis was used as for data that were not normally distributed (eg. age).

Statistical differences were computed at the $1 \%$ (0.01) significance level. This conservative significance level was chosen because a large number of comparisons were made and this was to reduce the risk of a Type 1 error, where statistical association is the result of chance, as this is known to increase when large numbers of comparisons are made. A one-way analysis of variance was used to investigate the relationship between the scales of the three tools used and selected clinical and demographic variables. Non-parametric testing was used as various assumptions that apply to parametric techniques were not satisfied, namely the sample was non-random, the population was not normally distributed for numerous variables and the sample size was small ( $n=75)$. Independent variables included, education pathway (BMid or GradDip); full-time versus part-time work patterns; age (in three groups); clinical versus non-clinical role; continuity model versus non-continuity; metropolitan versus regional address; public versus private sector; and, career intentions such as considering leaving versus not, changing hours or not, changing or remaining in current area of practice.

\section{FINDINGS}

There were 75 respondents (66\% response rate). Of the respondents, 30 (40\%) were from the BMid cohort and 45 (60\%) from the GradDip cohort. All bar one were women with an age range from 27 to 56 years old (Table 1). The BMid participants were significantly older (mean 7.6 years) than the GradDip participants $(p=<0.01)$. Sixty-one percent of participants had children under the age of 16 living at home with them. Almost $80 \%$ reported being in a domestic relationship. Most participants were born in Australia (75\%) with the next highest countries of birth being the United Kingdom (7\%) and New Zealand (4\%). The remainder were from Asia, Europe, Africa and the Middle East. 
$<$ Table 1>

Career decisions and working patterns

Fifty-nine participants (79\%) reported currently working in midwifery. Of the $16(21 \%)$ participants not working as a midwife, $4(13 \%)$ were in the BMid cohort and $12(27 \%)$ in the GradDip cohort. There was no significant difference between the two educational groups in relation to their midwifery workforce participation $(p=0.9)$ (Table 2).

$<$ Table 2>

Dissatisfaction with midwifery and family commitments were the main reasons for not currently working in midwifery. The duration worked as a midwife prior to ceasing ranged from 6 months to 5 years. The mean age of those no longer working as midwives was 30 years (range 28-42) and 13 of those $(81 \%)$ had dependant children. Six midwifery-leavers (38\%) had obtained further qualifications in health-related specialities since leaving the profession.

Although these participants were not working in midwifery, when asked if they would recommend midwifery as a profession the majority $(n=14)$ still responded positively as evidenced here:

It's a wonderful profession and provides immense job satisfaction. I believe it is a truly special job (GradDip) and, It's an amazing job where you get to work with women and their families during a very important life event (BMid).

Only two of the 16 participants who were no longer working as midwives stated they would not recommend midwifery as a career. In addition, of the 16 not currently working in midwifery, 12 (75\%) reported considering a return to the midwifery workforce in the near future. 
Of the 59 participants (79\%) who reported currently working in midwifery, $46 \%$ worked fulltime, $34 \%$ part-time, $14 \%$ were employed on a casual basis and $3 \%$ were either self-employed or undertook agency work. Table 3 provides detailed workforce participation patterns for both groups.

$<$ Table 3>

The BMid group were older than the GradDip group (41 vs 33 years; $p=<0.01$ ). The overall retention rate for the cohort was $79 \%$, with differences between the groups ( $87 \%$ vs $73 \%$ respectively; $p=0.2$ ). Twenty (27\%) had obtained further qualifications, most of which were within the health disciplines. Many were midwifery related and could be utilised to further their careers within the midwifery profession or move outside of midwifery but remain within a health discipline. Almost all $(n=52 / 59$; $88 \%)$ planned to continue to work as a midwife. Just over half of the participants had never considered leaving the midwifery profession $(n=32 ; 54 \%)$, whilst $39 \%$ had in the past $(n=23)$. Only four $(7 \%)$ were currently considering leaving midwifery.

The top three reasons for considering leaving midwifery were: self-reported burnout $(n=11)$, the unpredictable nature of shift work/ long hours $(n=5)$ and staff shortages $(n=3)$. Nearly half of the participants planned to stay in their current role $(n=27 ; 46 \%)$, and the majority would recommend midwifery as a career to others $(n=52 ; 88 \%)$.

More GradDip participants were working in a full-time basis than the BMid group ( $58 \%$ vs $23 \%$ ), however, apart from age, with the BMid cohort being significantly older than the GradDip cohort, there were no significant differences in regard to the educational pathway to midwifery and workforce patterns (Table 4).

$<$ Table 4>

Maslach Burnout Inventory

Maslach Burnout Inventory (MBI) scores revealed moderate levels of emotional exhaustion, low level of depersonalisation and low levels of reduced personal accomplishment in the 59 participants 
who were working as midwives (Table 5). There were no overall differences between the cohorts in the three MBI subscales. When assessing subscales scores, those participants who had seriously considered leaving scored higher on all the Emotional exhaustion and Depersonalisation subscales and lower on the Reduced personal accomplishment subscale, suggesting these participants, as compared to those who had not considered leaving, perceived a lack of enthusiasm and motivation and feelings of cynicism and ineffectiveness. Participants working in a continuity of care model had a significantly lower score on the Depersonalisation subscale $(M d=0.5, n=12)$ compared with those working in a non-continuity role $(M d=2.0, n=55)$ ( $p$ value $\leq 0.01)$. This suggests that those midwives working in a continuity role experience less unfeeling and impersonal responses toward women in their care. There were no other significant differences between the cohorts.

\section{Practice Environment Scale}

Participants considered that their workplaces were favourable work environments with only one area scoring unfavourably. Participants held negative impressions of the staffing and resources in their practice environments as indicated by the Staffing and resources subscale scores. Midwives working in a continuity role felt more favourable about midwifery professional development in their practice environments as opposed to those midwives working outside of this model (Foundations for quality midwifery care (continuity $M d=3.06, n=12$ vs $M d=2.78, n=53 ; p \leq 0.01$ ) although the overall numbers were small. There were no others differences seen between the cohorts.

Perceptions of Empowerment in Midwifery Scale (PEMS)

In the PEMS, possible scores range from 3-5 (very high perceived empowerment) to 13-15 (very low perceived empowerment). Overall, the participants were in the highest empowerment category in the total PEMS. No significant differences were seen between the cohorts. With regards to the subscale scoring, the higher the subscale score, the lower the level of perceived empowerment. There were significant differences in the Woman-centred subscale between those working in a continuity role $(M d=1.3, n=12)$ compared with those who did not $(M d=2.0, n=57 ; p$ value $\leq 0.01)$. 
The Autonomous Practice subscale result also suggested that those midwives working in continuity roles perceived that they had more autonomy in their work $(M d=1.8, n=12)(M d=2.3, \mathrm{n}=57 ; p$ $\leq 0.01)$. Those participants who had considered leaving midwifery altogether scored lower on the Woman-centred practice subscale $(M d=2.00, n=27$ vs $M d=1.6, n=32 ; p \leq 0.01)$, whilst those participants who had considered working in another area scored lower in both the Woman-centred practice and Autonomous practice subscales. These findings suggest that those midwives (i) working in continuity role; or (ii) not wanting to work in another midwifery area; or (iii) not having considered leaving the midwifery profession perceived their practice to be more woman-centred and autonomous in nature.

$<$ Table 5>

Future plans for those currently working in midwifery

Almost all those currently working in midwifery $(n=52 / 59 ; 88 \%)$ planned to continue to work as a midwife. Just over half of the participants had never considered leaving the midwifery profession ( $n$ $=32 ; 54 \%)$, whilst $39 \%$ had in the past $(n=23)$. Only four $(7 \%)$ were currently considering leaving midwifery. The majority would recommend midwifery as a career to others ( $n=52 ; 88 \%$ ) (Table 4).

\section{DISCUSSION}

The aim of this study was to explore the midwifery workforce experiences and participation in graduates six to seven years after completing either a post-nursing Graduate Diploma in Midwifery (GradDip) or an undergraduate degree, the Bachelor of Midwifery (BMid), from one university in New South Wales, Australia. The only statistically significant difference between the graduates from the two education pathways was age, with BMid graduates being older. There were no statistical differences in almost all other measures however there were some interesting trends identified in the sub-scale analysis especially related to midwifery continuity of care.

This study has used a number of validated workforce tools to generate midwifery specific data for this mid-career workforce. This is important as unfortunately accessing midwifery workforce data 
separate to nursing has been challenging although this is slowly improving with emerging Australian midwifery-specific workforce evidence..$^{3,11,14,22,31,32}$ The ability to research midwifery workforce issues has been supported by introduction of health practitioner regulation in 2010 and the subsequent recognition in national law of midwifery as a distinct profession..$^{32}$ Prior to 2012 , midwifery workforce data were analysed and presented in combination with nursing data and unfortunately this continues to occur in many studies.

The regulatory body for health practitioners in Australia undertakes an annual workforce survey on renewal of authorisation to practice and has a $97 \%$ completion rate. ${ }^{33}$ Since 2012 , the Australian Institute of Health and Welfare (AlHW) has provided more accurate national midwifery-specific data though analysing only those respondents working in midwifery. ${ }^{34}$ In 2015 , in their focus on midwifery data, the AlHW showed that almost all employed midwives were female (98.6\%) and more than $88 \%$ of midwives also held registration as a nurse. ${ }^{34}$ Given more than $88 \%$ of respondents are also registered as nurses it continues to be difficult to accurately predict current and projected midwifery workforce as respondents can be working hours in both midwifery and nursing and these may vary. This lack of long-term high quality midwifery specific data has contributed to the workforce and educational challenges facing Australian midwifery today. ${ }^{4}$

Another challenge is the age of midwives in Australia. The AlHW midwifery data indicate that the average age of employed midwives was 47.9 years and $52.3 \%$ were aged over $50 .{ }^{34}$ The mean age for all participants in our study was 35.8 years, 12.1 years younger than the average age of the employed midwife although this probably reflects career stage. This is reassuring as both groups studied were in their mid-career period so it could be expected that they would have many more productive working years ahead of them. However, this may not be the case if social research in regard to the differences between generations proves correct. ${ }^{35}$ Over the next 10 years, the generation referred to as the Millennials will become the majority in the workforce and Deloitte's annual 2016 Millennial Survey identifies that in regard to retention in the workforce this generation 
of workers have 'one foot out the door' with almost half of respondents indicating they plan to leave their current organisation within two years. ${ }^{36}$ Although this research was undertaken in the business sector there may be implications for the health sector and retention strategies need to be considered to assist with future-proofing the midwifery workforce.

Analysis of the subscales of the instruments used identified a number of protective aspects in regard to remaining in midwifery. Participants who had considered leaving midwifery perceived less enthusiasm and motivation and greater cynicism and ineffectiveness, all of these being burnout measures ${ }^{37}$ Working in a continuity of care model appeared to be protective against these same negative factors. In addition, more of the midwives who worked in continuity models of care felt more favourable about midwifery professional development in their practice environment, and regarded their practice to be more woman-centred and autonomous. These are not unusual findings and are supported by a number of studies investigating emotional wellness and burnout in midwifery. ${ }^{30,31,38,39}$ Another study that used the PEMS and PES scales found that providing continuity of care in a caseload model in New Zealand proved protective in regard to levels of burnout and better emotional health than working in standard shift-based models of care provision. ${ }^{40}$ In our study, there was no significant difference in educational pathway of those midwives who identified working in a continuity model and $17 \%$ of those midwives currently working in midwifery reported working this way.

Almost all participants who were currently working as a midwife stated that they intended to remain in this profession. Furthermore, for those who were not currently working as a midwife, $75 \%$ were considering a return to midwifery. The main reasons stated for not currently working in midwifery were dissatisfaction with midwifery and family commitments, with family commitments being most common. Family commitments could also explain the fact that more than half of the participants worked in a part-time or casual capacity. The tendency to work part-time is generated from the accessibility of part-time positions due to the shift work system of the midwifery workforce, as well 
as family commitments resulting from childrearing in the overtly female composition of the workforce. The AlHW, in their nursing and midwifery workforce report showed that the average working hours for nurses and midwives were 33.5 per week. ${ }^{41}$ The mean hours per week in this study was similar at 31 hours. Given more than half of the participants in the study chose to work part-time, as is the case with nursing and midwifery nationally, increased flexibility in working hours and opportunities for part-time positions would most likely assist workforce retention..$^{42}$ Mason ${ }^{43}$ in her review on health workforce programs identified strategies such as enabling midwives to work at their full scope of practice, best able in a continuity of care model, and flexible work arrangements as key to supporting practitioners with family commitments and retaining workers in the workplace.

\section{Limitations}

Due to the sample size, the single recruitment setting of one Australian university, and the inclusion of only two of the three available midwifery pathways in Australia, the external validity and generalisability of the findings of this study cannot be assured. However, the university in which the study was undertaken is fairly typical of Australian midwifery programs given all follow the same standards and the employment opportunities in this state are broadly similar across the country. It is likely therefore that the findings are illustrative of many Australian midwives. Unfortunately, as is known to occur in time-dependant longitudinal studies, numerous participants were not contactable via previously supplied addresses and so were not able to be included. Given the sample size, we suggest further studies are undertaken that track workforce experiences from other programs and in other parts of Australia. In addition, additional research based on qualitative research designs would be useful and important.

\section{Conclusion}

This examination of the early to mid-career midwifery workforce participation and decisions of graduates from two different education pathways has demonstrated that apart from age, differences between the cohorts are not evident. The BMid graduates in this study were more than 
seven years older than the GradDip prepared graduates but when compared to Australian midwives' average age the participants in the study was around 12 years younger.

There were no significant differences in terms of burnout measures, workforce participation, turnover, intention to leave and work patterns between the groups. It is possible that continuity of midwifery care was protective with lower levels of cynicism and higher levels of enthusiasm and motivation in regard to the profession. Almost all midwives currently working in midwifery intended to remain in the profession and three-quarters of those who had left midwifery were considering returning.

Regardless of educational pathway to midwifery, mid-career trajectories (that is six to seven years post-graduation) are no different between these two pathways which is encouraging. Given both pathways are offered across Australia, it is reassuring to note that there is no statistically significant difference in the midwifery workforce and professional measures of these graduates. This research adds to the growing midwifery-specific workforce evidence and further supports available evidence that emotional wellbeing, flexible work practises and the relational aspects of midwifery support retention and longevity in midwifery workforce.

\section{Acknowledgments}

We wish to acknowledge the midwives who gave their time to be involved in this research. The research was supported through a university PhD Chancellor's Scholarship. 
Table 1: Demographic characteristic by BMid and GradDip cohorts

\begin{tabular}{|l|c|c|c|}
\hline Variable & $\begin{array}{l}\text { GradDip } \\
n=45(\%)\end{array}$ & $\begin{array}{l}\text { BMid } \\
n=30(\%)\end{array}$ & P value \\
\hline \multicolumn{4}{|c|}{ Mean (range) } \\
\hline Age (years) & $32.8(27-56)$ & $40.4(27-54)$ & $<0.01$ \\
\multicolumn{4}{|c|}{$n(\%)$} \\
\hline Children (<16 years old) living at home & $20(44.4 \%)$ & $9(30 \%)$ & \\
- None & $25(55.6 \%)$ & $21(70 \%)$ & $p=0.2$ \\
- 1 or more & $10(22.2 \%)$ & $6(20 \%)$ & \\
\hline Domestic partner & $35(77.8)$ & $24(80 \%)$ & $p=0.8$ \\
- None & $23(76.6 \%)$ & $33(73.3 \%)$ & \\
\hline Country of Birth & $2(6.7 \%)$ & $3(6.7 \%)$ & \\
- Australia & $1(3.3 \%)$ & $2(4.4 \%)$ & \\
- United Kingdom $\quad$ New Zealand & $4(13.3)$ & $7(15.6 \%)$ & $p=0.9$ \\
\hline$\quad$ Other & \multicolumn{2}{|c|}{} \\
\hline
\end{tabular}


Table 2: Workforce Participation trends by BMid and GradDip cohorts

\begin{tabular}{|l|c|c|c|}
\hline Variable & $\begin{array}{l}\text { GradDip } \\
n=\mathbf{4 5}(\%)\end{array}$ & $\begin{array}{l}\text { BMid } \\
n=30(\%)\end{array}$ & P value \\
\hline \multicolumn{3}{|c|}{ Midwifery workforce participation trends } \\
\hline Still in midwifery practice & $33(74 \%)$ & $26(87 \%)$ & \\
\cline { 2 - 3 } Never practised midwifery & $2(4 \%)$ & $2(7 \%)$ & \multirow{2}{*}{$p=0.9$} \\
\cline { 2 - 3 } Practised midwifery returned to nursing & $4(9 \%)$ & $\mathrm{n} / \mathrm{a}$ & \\
\cline { 2 - 3 } $\begin{array}{l}\text { Practised midwifery went into another career } \\
\text { Practised midwifery then retired from the workforce }\end{array}$ & $613 \%)$ & $2(7 \%)$ & \\
\cline { 2 - 3 } & $0(0 \%)$ & $0(0 \%)$ & \\
\hline
\end{tabular}


Table 3: Frequency of workforce patterns in BMid and GradDip cohorts

\begin{tabular}{|c|c|c|c|c|c|c|}
\hline \multirow{2}{*}{$\begin{array}{l}\text { Variable } \\
\begin{array}{l}\text { Number of hospitals } \\
\text { employed by }\end{array}\end{array}$} & \multicolumn{2}{|l|}{$\begin{array}{l}\text { BMid } \\
(n=26)\end{array}$} & \multicolumn{2}{|l|}{$\begin{array}{l}\text { GradDip } \\
(n=33)\end{array}$} & \multicolumn{2}{|l|}{$\begin{array}{l}\text { Total } \\
(n=59)\end{array}$} \\
\hline & Frequency & Percent & Frequency & Percent & Frequency & Percent \\
\hline 1 & 9 & 35 & 18 & 55 & 27 & 46 \\
\hline 2 & 10 & 38 & 12 & 36 & 22 & 37 \\
\hline 3 & 5 & 19 & 0 & 0 & 5 & 8.5 \\
\hline$\geq 4$ & 2 & 8 & 3 & 9 & 5 & 8.5 \\
\hline Total & 30 & 100 & 45 & 100 & 75 & 100 \\
\hline \multicolumn{7}{|l|}{$\begin{array}{l}\text { Length of time worked at } \\
\text { current hospital }\end{array}$} \\
\hline$<6$ months & 2 & 8 & 2 & 6 & 4 & 7 \\
\hline 6-12 months & 1 & 4 & 0 & 0 & 1 & 2 \\
\hline $1-3$ years & 8 & 33 & 6 & 18 & 14 & 25 \\
\hline 4-6 years & 13 & 55 & 25 & 76 & 38 & 66 \\
\hline Total & 24 & 100 & 33 & 100 & 57 & 100 \\
\hline \multicolumn{7}{|l|}{$\begin{array}{l}\text { Length of time worked in } \\
\text { current midwifery role }\end{array}$} \\
\hline$<6$ months & 2 & 8 & 6 & 18 & 8 & 12 \\
\hline 6-12 months & 3 & 12 & 3 & 10 & 6 & 11 \\
\hline $1-3$ years & 13 & 52 & 9 & 27 & 22 & 38.5 \\
\hline 4-6 years & 7 & 28 & 15 & 45 & 22 & 38.5 \\
\hline Total & 25 & 100 & 33 & 100 & 57 & 100 \\
\hline \multicolumn{7}{|l|}{$\begin{array}{l}\text { Title of current midwifery } \\
\text { role }\end{array}$} \\
\hline Clinical midwife & 23 & 88 & 24 & 73 & 47 & 80 \\
\hline Clinical midwifery specialist & 0 & 0 & 3 & 9 & 3 & 5 \\
\hline Management & 0 & 0 & 2 & 6 & 2 & 3 \\
\hline Clinical education & 0 & 0 & 3 & 9 & 3 & 5 \\
\hline Research & 1 & 4 & 0 & 0 & 1 & 2 \\
\hline Antenatal education & 1 & 4 & 1 & 3 & 2 & 3 \\
\hline $\begin{array}{l}\text { Privately practising } \\
\text { homebirth midwife }\end{array}$ & 1 & 4 & 0 & 0 & 1 & 2 \\
\hline Total & 26 & 100 & 33 & 100 & 59 & 100 \\
\hline \multicolumn{7}{|l|}{$\begin{array}{l}\text { Work area of current } \\
\text { midwifery role }\end{array}$} \\
\hline Rotational position & 6 & 23 & 10 & 30 & 16 & 27 \\
\hline Birthing wards & 6 & 23 & 8 & 24 & 14 & 24 \\
\hline Continuity of care model & 5 & 19 & 5 & 15 & 10 & 17 \\
\hline Antenatal/postnatal ward & 6 & 23 & 2 & 6 & 8 & 13 \\
\hline Parent education & 1 & 4 & 2 & 6 & 3 & 5 \\
\hline Antenatal clinic & 1 & 4 & 1 & 3 & 2 & 3 \\
\hline Midwifery education & 0 & 0 & 3 & 10 & 3 & 5 \\
\hline Community midwife* & 0 & 0 & 1 & 3 & 1 & 2 \\
\hline Private practice & 1 & 4 & 0 & & 1 & 2 \\
\hline Management & 0 & 0 & 1 & 3 & 1 & 2 \\
\hline
\end{tabular}




\begin{tabular}{|l|c|c|c|c|c|c|}
\hline Total & 26 & 100 & 33 & 100 & 59 & 100 \\
\hline $\begin{array}{l}\text { Work pattern of current } \\
\text { midwifery role }\end{array}$ & 17 & 65 & 16 & 49 & 33 & 56 \\
\hline $\begin{array}{l}\text { Combination AM/PM/night } \\
\text { shifts }\end{array}$ & 6 & 23 & 6 & 18 & 12 & 20 \\
\hline On call/continuity & 2 & 8 & 5 & 15 & 7 & 12 \\
\hline Day shift only & 1 & 4 & 4 & 12 & 5 & 9 \\
\hline Other & 0 & 0 & 2 & 6 & 2 & 3 \\
\hline Night shift & 26 & 100 & 33 & 100 & 59 & 100 \\
\hline Total & & & & & & \\
\hline
\end{tabular}

*Community midwife included Midwifery Support Program, outreach program, home visiting 
Table 4: Workforce patterns for those currently in working in midwifery by BMid and GradDip cohorts

\begin{tabular}{|l|c|c|c|}
\hline Variable & $\begin{array}{c}\text { GradDip } \\
\boldsymbol{n}=\mathbf{( \% )}\end{array}$ & $\begin{array}{c}\text { BMid } \\
\boldsymbol{n}=\mathbf{( \% )}\end{array}$ & $\begin{array}{l}\mathbf{P} \\
\text { value }\end{array}$ \\
\hline Average age & & & \\
Mean (Years) & $32.8(27-56)$ & $40.4(27-54)$ & $<0.01$ \\
\hline Currently working as a midwife & $33(73.3 \%)$ & $26(86.7 \%)$ & 0.1 \\
\hline Working pattern of currently working midwives & $19(57.7 \%)$ & $6(23.1 \%)$ & \\
- Full time & $9(27.2)$ & $12(46.2 \%)$ & \\
- Part time & $3(9.1 \%)$ & $6(23.1 \%)$ & 0.05 \\
- Casual & $2(6.0 \%)$ & nil & \\
- Self- employed & nil & $2(7.6 \%)$ & \\
\hline Undertaken further qualifications & $15(33.3 \%)$ & $11(33.7 \%)$ & 0.8 \\
\hline Plans to continue working in midwifery for currently & $29(87.9 \%)$ & $23(88.5 \%)$ & 0.9 \\
working midwives & & & \\
\hline Has considered leaving midwifery in the past & $13(39.4 \%)$ & $10(38.5 \%)$ & 0.2 \\
\hline Currently considering leaving midwifery & $4(12.1 \%)$ & nil & 0.2 \\
\hline Would recommend midwifery as a career to others & $31(93.9 \%)$ & $21(80.8 \%)$ & 0.1 \\
\hline
\end{tabular}


Table 5: Subscale scores for the Maslach Burnout Inventory by by BMid and GradDip cohorts

\begin{tabular}{|c|c|c|c|}
\hline & $\begin{array}{c}\text { GradDip } \\
\mathrm{N}=33 \\
\text { Mean (SD) }\end{array}$ & $\begin{array}{c}\text { BMid } \\
\mathrm{N}=26 \\
\text { Mean (SD) }\end{array}$ & $\begin{array}{l}P \\
\text { value }\end{array}$ \\
\hline \multicolumn{4}{|l|}{ MBI-HSS subscale scores } \\
\hline - Emotional exhaustion & $18.5(10.7)$ & $18.3(10.3)$ & NS \\
\hline - $\quad$ Depersonalisation & $4.3(4.4)$ & $3.8(6.6)$ & NS \\
\hline - Reduced personal accomplishment & $39.5(5.9)$ & $41.3(11.3)$ & NS \\
\hline \multicolumn{4}{|l|}{ PES-NWI subscale scores } \\
\hline - Midwife participation in hospital affairs & $2.64(0.47)$ & $2.45(0.48)$ & NS \\
\hline - Foundations for quality midwifery care & $2.81(0.42)$ & $2.81(0.49)$ & NS \\
\hline - Midwifery leadership & $2.76(0.54)$ & $2.71(0.71)$ & NS \\
\hline - Staffing and resources & $2.48(0.68)$ & $2.40(0.69)$ & NS \\
\hline - Midwife-doctor relationships & $3.0(0.63)$ & $2.87(0.62)$ & NS \\
\hline Total PES-NWI score & $5.99(1.17)$ & $7.13(1.96)$ & NS \\
\hline \multicolumn{4}{|l|}{ PEMS subscale scores } \\
\hline - Autonomous practice & $2.11(0.52)$ & $2.51(0.81)$ & NS \\
\hline - Effective management & $2.15(0.58)$ & $2.56(0.79)$ & NS \\
\hline - Woman-centred practice & $1.74(0.46)$ & $2.06(0.66)$ & NS \\
\hline
\end{tabular}

NS (not significant): $p>0.01$ 


\section{REFERENCES}

1. Renfrew $\mathrm{M}, \mathrm{McF}$ adden $\mathrm{A}$, Bastos $\mathrm{H}$, et al. Midwifery and quality care: findings from a new evidence-informed framework for maternal and newborn care. The Lancet 2014; 384: 112945.

2. Barry M, Hauck Y, O'Donoghue T, Clarke S. Newly-graduated midwives transcending barriers: mechanisms for putting plans into actions. Midwifery 2014; 30(8): 962-7.

3. Fenwick J, Hammond A, Raymond J, et al. Surviving, not thriving: a qualitative study of newly qualified midwives' experience of their transition to practice. J Clin Nurs 2012; 21(1314): 2054-63.

4. Gray JE, Smith RM. Any action? Reflections on the Australian Midwifery Action Project. Women Birth 2017; 30(3): 177-83.

5. Leap N, Brodie P, Tracy SK. Collective action for the development of national standards for midwifery education in Australia. Women Birth 2017; 30(3): 169-76.

6. Australian Nursing \& Midwifery Council. National competency standards for the midwife. Canberra: Australian Nursing and Midwifery Council; 2006.

7. Health Workforce Australia. Health Workforce 2025 - Doctors, Nurses and Midwives Volume 1. Adelaide: Health Workforce Australia, 2012.

8. Global Health Workforce Alliance. A Universal Truth: No Health Without a Workforce. Geneva: World Health Organization; 2013.

9. Health Workforce Australia. Health Workforce by Numbers - Issue 2. Adelaide: Health Workforce Australia; 2013.

10. Clements V, Fenwick J, Davis D. Core elements of transition support programs: The experiences of newly qualified Australian midwives. Sexual Reprod Healthcare 2012; 3(4): 155-62.

11. Cummins AM, Denney-Wilson E, Homer CSE. The experiences of new graduate midwives working in midwifery continuity of care models in Australia. Midwifery 2015; 13(4): 438-44.

12. Kensington $M$. The faces of mentoring in New Zealand: realities for the new graduate midwife.NZCOM Journal 2006; 35: 22-7.

13. van der Putten $\mathrm{D}$. The lived experience of newly qualified midwives: a qualitative study. $\mathrm{Br} J$ Midwifery 2008; 16(6): 348-58.

14. Hammond A, Gray J, Smith R, Fenwick J, Homer C. Same ... Same but different: expectations of graduates from two midwifery education courses in Australia. J Clin Nurs 2011; 20(15-16): 2315-24.

15. Curtis $P$, Ball L, Kirkham M. Ceasing to practise midwifery: working life and employment choices. Br J Midwifery 2006; 14(6): 336-8.

16. Hildingsson I, Westlund K, Wiklund I. Burnout in Sweish midwives. Sexual Reprod Healthcare 2013; 4(3): 87-91.

17. Shen J, Cox A, McBride A. Factors influencing turnover and retention of midwives and consultants: a literature review. Health Services Management Res 2004; 17(4): 249-62.

18. Cameron C. Becoming and being a midwife: A theoretical analysis of why midwives leave the profession. Can J Midwifery Res Practice 2011; 10(2): 22-8.

19. Curtis $\mathrm{P}$, Ball L, Kirkham M. Why do midwives leave? (Not) being the kind of midwife you want to be. Br J Midwifery 2006; 14(1): 27-31.

20. Kirkham M, Morgan R, Davies C. Why Do Midwives Stay? Sheffield: Women's Informed Childbearing and Health Research Group: University of Sheffield; 2006.

21. Scott A, Witt J, Duffield C, Kalb G. What do nurses and midwives value about their jobs? Results from a discrete choice experiment. J Health Services Res Policy 2015; 20(1): 31-8.

22. Sullivan K, Lock L, Homer C. Factors that contribute to midwives staying in midwifery: A study in one Area Health Service in New South Wales, Australia. Midwifery 2011; 27(331335). 
23. Maslach C, Jackson SE. The measurement of experienced burnout. J Organizational Behaviour 1981; 2(2): 99-113.

24. Galanakis M, Moraitou M, Garivaldis FJ, Stalikas A. Factorial structure and psychometric properties of the Maslach Burnout Inventory (MBI) in Greek midwives. Euro J Psychology 2009; 5(4): 52-70.

25. Schutte N, Toppinen S, Kalimo R, Schaufeli W. The factorial validity of the Maslach Burnout Inventory-General Survey (MBI-GS) across occupational groups and nations. J Occupat Organiz Psychology 2000; 73(1): 53-67.

26. Parker D, Tuckett A, Elay R, Hegney D. Construct validity and reliability of the Practice Environment Scale of the Nursing Work Index (PES-NWI) for Queensland Nurses. Int $J$ Nursing Practice 2010; 16(4): 352-8.

27. Pallant JF, Dixon L, Sidebotham M, Fenwick J. Adaptation and psychometric testing of the Practice Environment Scale for use with midwives. Women Birth 2016; 29(1): 24-9.

28. Matthews A, Scott P, Gallagher P. The development and psychometric evaluation of the Perceptions of Empowerment in Midwifery Scale. Midwifery 2009; 25(3): 327-35.

29. SPSS Inc. IBM SPSS Statistics for Windows (Version 22.0). Chicago: IBM Corporation; 2013.

30. Jordan K, Fenwick J, Slavin V, Sidebotham M, Gamble J. Level of burnout in a small population of Australian midwives. Women Birth 2013; 26(2): 125-32.

31. Newton $\mathrm{M}$, Forster $\mathrm{D}$, McLachlan $\mathrm{H}$. Exploring satisfaction and burnout among caseload and non-caseload midwives. Women and Birth 2011; 24(1): S13.

32. Health Practitioner Regulation National Law and Other Legislation Amendment Act 2017. Australia: Queensland Government; 2017.

33. Australian Health Practitioners Regulation Agency (AHPRA). AHPRA Annual Report Performance Summary. Melbourne: Australian Health Practitioners Regulation Agency, 2017.

34. Australian Institute of Health and Welfare. Focus on Midwives. Canberra: Australian Government Austalian Institute of Health and Welfare https://www.aihw.gov.au/reports/workforce/nursing-and-midwifery-workforce2015/contents/focus-on-midwives Accessed 2 April 2018.

35. Catalyst. Revealing the Real Millennials: Career Expectations. New York: Catalyst, 2015.

36. Deloitte Touche Tohmatsu Limited. The 2016 Deloitte Mellenial Survey United Kingdom: Deloitte Touche Tohmatsu Limited, 2016.

37. Maslach C, Jackson SE, Leiter MP. Maslach Burnout Inventory manual. 3rd ed. Palo Alto: Consulting Psychologists Press; 1996.

38. Sandall J. Team midwifery and burnout in midwives in the UK: practical lessons from a national study. MIDIRS Midwifery Digest 1999; 9(2): 147-52.

39. Yoshida Y, Sandall J. Occupational burnout and work factors in community and hospital midwives: a survey analysis. Midwifery 2013; 29(8):921-6.

40. Dixon L, Guilliland K, Pallant J, et al. The emotional wellbeing of New Zealand midwives: Comparing responses for midwives in caseloading and shift work settings. NZCOM Journal 2017; (53): 5-14.

41. Australian Institute of Health and Welfare. Work characteristics of nurses and midwives. 2015. https://www.aihw.gov.au/reports/workforce/nursing-and-midwifery-workforce2015/contents/work-characteristics-of-nurses-and-midwives. Accessed 2 April 2018.

42. Australian Bureau of Statistics. Patterns in work. 2009. http://www.abs.gov.au/AUSSTATS/abs@.nsf/Lookup/4102.0Main+Features50Dec+2009 Accessed 2 April 2018.

43. Mason J. Review of Australian Government Health Workforce Programs Canberra: Australian Government, 2013. 